\title{
BMJ Open Characteristics and prognoses of patients treated by an anaesthesiologist- manned prehospital emergency care unit. A retrospective cohort study
}

\author{
Søren Mikkelsen,, ${ }^{1,2}$ Hans Morten Lossius,, ${ }^{3,4}$ Palle Toft,, ${ }^{2,5}$ \\ Annmarie Touborg Lassen ${ }^{2,6}$
}

To cite: Mikkelsen S, Lossius HM, Toft P, et al. Characteristics and prognoses of patients treated by an anaesthesiologistmanned prehospital emergency care unit. A retrospective cohort study. BMJ Open 2017;7:e014383. doi:10.1136/bmjopen-2016014383

- Prepublication history and additional material is available. To view please visit the journal (http://dx.doi.org/ 10.1136/bmjopen-2016014383).

Received 21 September 2016 Revised 25 January 2017 Accepted 31 January 2017

CrossMark

For numbered affiliations see end of article.

Correspondence to Dr Søren Mikkelsen; soeren.mikkelsen@rsyd.dk

\section{ABSTRACT}

Objective: When planning and dimensioning an emergency medical system, knowledge of the population serviced is vital. The amount of literature concerning the prehospital population is sparse. In order to add to the current body of literature regarding prehospital treatment, thus aiding future public health planning, we describe the workload of a prehospital anaesthesiologist-manned mobile emergency care unit (MECU) and the total population it services in terms of factors associated with mortality.

Participants: The study is a register-based study investigating all missions carried out by a MECU operating in a mixed urban/rural area in Denmark from 1 May 2006 to 31 December 2014.

Information on missions was extracted from the local MECU registry and linked at the individual level to the Danish population-based databases, the National Patient Registry and the Civil Registration System.

\section{Primary and secondary outcome measures:}

Primary outcome measures were number of missions and number of patient contacts. Secondary patient variables were mortality and association between mortality and age, sex, comorbidity, prior admission to hospital and response time.

Results: The MECU completed 41513 missions (mean 13.1 missions/day) having 32873 patient contacts, corresponding to 19.2 missions and 15.2 patient encounters per 1000 patient years. Patient variables: the median age was 57 years (range 0-108 years), $42.8 \%$ (42.3\% to $43.4 \%$ ) were women. For patients admitted to hospital alive, 30-day mortality was $5.7 \%$ (5.4\% to $6.0 \%$ ); 90 -day mortality was $8.1 \%(7.8 \%$ to $8.5 \%)$ while 2-year mortality was $16.4 \%(16.0 \%$ to $16.8 \%)$. Increasing age, male sex, comorbidity and prior admission to hospital but not response time were associated with mortality.

Conclusions: Mortality following an incident requiring the assistance of a MECU was high in the first 2 years following the incident. MECU response time assessed as a continuous parameter was not associated with patient outcome.

\section{Strengths and limitations of this study}

- The study comprises a large number of patients treated by a physician manned prehospital mobile emergency care.

- Very few patients were lost to follow-up.

- As the study is a single-centre study and based on a one International Statistical Classification of Diseases and Related Health Problems 10th Revision (ICD-10) classification code per patient, and as assessment of the association between comorbidity and outcomes is based on information extracted from hospitals only, any generalisation must be made with caution.

\section{INTRODUCTION}

The prognosis for patients with severe injury or illnesses is closely related to correct and early treatment. ${ }^{1-4}$ Patient outcomes may thus depend on the diagnostic and interventional proficiencies within the prehospital systems. For selected patient groups, an appropriately trained physician may provide superior diagnostics and treatment, compared with other emergency medical care providers, impacting on patient outcome. ${ }^{5}$

Based on this assumption, publicly funded anaesthesiologist-staffed prehospital services have developed in Scandinavia over the last 40 years. They are now a central and integrated part of the prehospital emergency medical systems (EMS), though their number of patient encounters varies somewhat within the Scandinavian countries. ${ }^{6}$

In Denmark, the emergency medical service is regulated by law. ${ }^{7}$ The nationally implemented system is a publicly funded, three-tiered system in which the basic resource is an ambulance manned by two emergency medical technicians. The prehospital resource is dispatched by a dispatch centre, where the dispatcher dispatches an 
ambulance, an ambulance and a paramedic, or an ambulance and an anaesthesiologist-manned MECU. ${ }^{8}$ Several studies have investigated the effects of increasing the therapeutic capabilities of prehospital care providers by using specially trained physicians at the prehospital scene. $^{5}{ }^{6}{ }^{9-14}$ These services demand more resources and are more expensive than services staffed with emergency medical technicians or paramedics, and as the evidence base of the superiority of these services is currently weak, more research is demanded to evaluate the effect and efficiency. ${ }^{15}$

An understanding of the characteristics of the population serviced is a prerequisite for rational public health planning. However, the current knowledge of the population served by these specialised EMS is sparse and has predominantly been focusing on selected patient groups such as paediatric, ${ }^{16}{ }^{17}$ geriatric $^{18-21}$ and trauma patients. ${ }^{22}$ Although some studies have attempted to describe the general prehospital population serviced by a basic emergency medical service, ${ }^{2021} 23$ only two previous attempts have been made to characterise the population or the services of an anaesthesiologist-manned advanced emergency medical service. ${ }^{6}{ }^{24}$ Intuitively, it may be expected that the mortality of the patients treated by the mobile emergency care unit (MECU) would be higher than the background population. However, neither the extent nor the degree of this presumed higher mortality following an incident requiring the assistance of the MECU has been established.

To increase our knowledge in the field, and thus to aid future planning of emergency medical services, this study aims to describe the workload of a MECU manned with a specially trained anaesthesiologist operating in a mixed urban and rural area. Furthermore, the study aims to investigate the characteristics and prognosis of the population treated by this MECU.

\section{MATERIAL AND METHODS}

\section{Study setting and population}

The study is a retrospective cohort study carried out on the MECU in Odense, the largest city in the region of southern Denmark. In this region, a MECU is on average engaged in $26.2 \%$ of all emergency runs.

The MECU in Odense consists of one rapid-response car, operating all year round, manned with a specialist in anaesthesiology and an emergency medical technician. The MECU in Odense covers $\sim 2500 \mathrm{~km}^{2}$ while servicing a population of $\sim 250000$. The MECU in Odense refers almost all patients to Odense University Hospital, the largest teaching hospital in the region of southern Denmark. Apart from being dispatched by the dispatch centre, the MECU also responds to requests for assistance from the emergency medical technicians in the ambulance if needed. Furthermore, the MECU handles missions of lesser urgency: involuntary admission to hospitals of psychotic patients and assisting the police in evaluation of particular patients. These missions are all handled as non-emergency runs. After concluding any MECU run, the anaesthesiologist documents the details of the mission in a registry identifying the patient via the patient's unique civil personal register (CPR) number. ${ }^{25}$ If a patient is initially unidentified, an interim CPR number is constructed thus enabling coupling of data to the patient on proper identification. The physician registers the MECU response time, the diagnosis, the treatment administered, as well as procedures performed. Also, the physician classifies the type of mission completed:

- patient released at the scene or admitted to hospital by ambulance with or without physician escort;

- patient declared dead with or without reliable signs of death;

- mission down-prioritised before or after patient contact in favour of other mission;

- MECU cancelled by ambulance;

- stand-by missions (fires, police actions);

- patient not found;

- miscellaneous.

Along with the registration, the physician documents the emergency run with a discharge summary which is transferred to the hospital and to the patient's general practitioner.

The CPR number is validated by internal control during entering of data, with the MECU registry actively informing the physician if an entered number does not fulfil the criteria for a legitimate CPR number. For patients who are unidentified at the time of MECU contact, the correct CPR number is assigned to the patient by a medical secretary who subsequently contacts the hospital and obtains a correct identification of the patient. The corrected identification number is then linked to the patient by the medical secretary who re-enters the information in the database.

\section{Study design}

A retrospective cohort study of all Odense MECU missions from 1 May 2006 until 31 December 2014 was carried out. Information on all missions was extracted and linked at the individual level to large Danish population-based databases.

We used the Civil Registration System and the National Patient Registry. ${ }^{25}{ }^{26}$ Standard mortality rates were calculated from StatBank Denmark. ${ }^{27}$ Data from the MECU registry, the Danish National Patient Register and the Danish Civil Registration system were merged at the individual level by use of the CPR number assigned to all Danish residents. ${ }^{25}$

\section{Inclusion criteria}

For system descriptive parameters (number of emergency runs and mission outcome) and diagnosis assigned prehospitally, all records from the period 1 May 2006 to 31 December 2014 were considered. For patient descriptive parameters, all identifiable patients were included. 


\section{Exclusion criteria}

Patients who remained unidentified and patients with an invalid CPR number were excluded from mortality analysis and analyses relating to age or sex.

\section{Variables}

All parameters were extracted electronically.

From the MECU registry, we extracted the number and classification of missions, response time, the patients' CPR number, age, sex and International Statistical Classification of Diseases and Related Health Problems 10th Revision (ICD-10) classified diagnosis as assigned to the patient by the MECU physician at the scene. $^{28}$

From the Danish National Patient Register, ${ }^{26}$ we extracted the discharge diagnoses 10 years prior to index date. These were used to calculate the Charlson Comorbidity Index (CCI) ${ }^{29}$ Furthermore, we extracted the number of days admitted to hospital within 180 days leading up to the event. In cases where more than one contact with the MECU was registered, the first contact was used in relation to calculations pertaining to mortality.

From the Civil Registration System ${ }^{25}$ we extracted the time of death following the first contact with the MECU and the migration status of the patients.

In order to procure a standard mortality figure applicable to the catchment area of the MECU, we extracted the population size and overall mortality rates from StatBank Denmark. ${ }^{27}$

\section{Missing data and control of outliers}

Missing data were handled as such and not substituted.

Previous internal quality assurance assessments have shown that taking all urgent and non-urgent administrative types of missions in the catchment area into consideration, response times do not exceed $50 \mathrm{~min}$. Response time values below $1 \mathrm{~min}$ and over $50 \mathrm{~min}$ were thus considered erroneous and excluded.

\section{Descriptive analysis and statistical methods}

Data were presented as proportions, median and quartiles or range (where appropriate). Proportions are presented with $95 \%$ CIs based on a binomial distribution. All data were analysed using non-parametric statistics $\left(\chi^{2}\right.$ or Kruskal-Wallis). Differences were considered significant when $\mathrm{p}<0.05$.

\section{Mortality compared with the background population}

The principle of dispatching the nearest available MECU to incidents in the region precludes us from defining a fixed catchment area. The approximated reference mortality was therefore derived from the four municipalities that constitute the general catchment area of Odense University Hospital. Over a period of 6 years (2009-2014), the mortality of this population was compared with the mortality calculated from the total cohort of MECU patients at 0-7 days, 8-30 days, 31-90 days and
91-730 days following first MECU contact. Mortality was calculated as a function of patient-years at risk. Age was divided into integers of 10 years up to $90+$ years.

In order to reduce any residual effects from the immediate period before inauguration of the MECU which might introduce survival bias, when analysing data on mortality and prognostic factors, we eliminated observations taking place in the first year following the inauguration of the MECU. This left truncation meant that sampling of data regarding mortality and factors associated with death was started on 1 May 2007 (1 year following the inauguration of the MECU). The inclusion of patients was terminated on 31 December 2014 while follow-up (via the National Patient Register and the Civil Registration System) was continued until 30 June 2015.

Patients were followed until death, emigration, 2 years of follow-up or 30 June 2015, whichever came first.

\section{Survival analysis}

Survival is presented by Kaplan-Meier survival curve and applied for the total population and for the subpopulations diagnosed within ICD-10 chapters IX (diseases of the circulatory system), $\mathrm{X}$ (diseases of the respiratory system), XVIII (symptoms, signs and abnormal clinical and laboratory findings, not elsewhere classified), XIX (injury, poisoning and certain other consequences of external causes) and XXI (factors influencing health status and contact with health services) including all patients with the first contact with the MECU from 1 May 2007. Patients entered into the survival analysis were followed until death, emigration or 30 June 2015, whichever came first.

\section{Factors associated with death}

Among all first time MECU contacts, a multivariate Cox proportional hazard regression analysis was applied to investigate association between mortality and sex, age, CCI $(0,1-2$ and $>2)$, number of weeks admitted to hospital 180 days leading up to contact with the MECU and response time at $0-7$ days, $8-30$ days, $31-90$ days and $91-$ 730 days following first MECU contact.

The proportional assumption was checked by manual inspection of $\log$ (cumulative hazard) versus log (time) plots. $^{30}$

All statistical calculations were performed using STATA 14.1 (StataCorp, Texas, USA).

Data are presented according to a previously presented consensus-based template, ${ }^{31}$ and results are presented in accordance with the Strengthening the Reporting of Observational Studies in Epidemiology (STROBE) criteria. $^{32}$

\section{Ethics}

The study was approved by the Danish Data Protection Agency (2014-41-3305) and the Danish Health and Medicines Agency (3-3013-682/1/). Approval by an Ethics Committee or informed consent is not required for register-based research in Denmark. 


\section{RESULTS}

\section{Mission characteristics}

From 1 May 2006 to 31 December 2014, the MECU was assigned to 41513 missions: mean 13.1 per day, range 1-25 per day. On average, the MECU was dispatched to one more contact on Fridays than on other days. The number of missions corresponds to 19.1 missions per 1000 patient years. Of these, 15.2 missions per 1000 patient years resulted in a patient encounter. In $8571(20.6 \%)$ contacts, the mission was completed without patient contact: In $6887(16.6 \%)$ cases, the MECU was cancelled by the ambulance personnel before patient contact. In 1278 (3.1\%) cases, the MECU physician down-prioritised a mission in favour of another mission. Almost $1 \%$ of missions were stand-by missions or other missions without patient contact. In the 32873 (79.2\%) missions with patient contact, $3211(9.8 \%)$ patients were declared dead at the scene, $4286(10.3 \%)$ were treated and subsequently released at the scene and $24200(58.3 \%)$ were transported to the hospital (figure 1). The total number of patients with more than one contact was $789(2.7 \%)$, with the total number of repeated contacts being 4075 (range 2-50 contacts).

The median response time was 8 minutes (5-12 min); range 1-50 min (see online supplementary figure $\mathrm{S} 1$ ). Three hundred twenty-nine response times under $1 \mathrm{~min}$ and 91 response times over $50 \mathrm{~min}$ were considered erroneous and discarded. Four hundred forty-seven response times were missing.

\section{Patient characteristics}

Sex was registered in 32773 patient contacts, 14033 (42.8\% (95\% CI $42.3 \%$ to $43.4 \%$ ) being women.

Age was registered in 32682 , the median age being 57 years (range $0-108$ years).

Women were older than men (58 years $(31-77)$ vs 56 years $(34-71) \mathrm{p}<0.001)$ (figure 2 age and sex).

The total number of first time contacts was 28743 patients. In 28028 of these patients, a valid Danish CPR number was available, and these patients could be followed beyond the prehospital phase. In these firstcontact patients, the CCI, based on discharge diagnoses 10 years prior to index date, ranged from 0 to 17 with a median (quartiles) of $0 \quad(0-2) . I n \quad 51.05 \% \quad(95 \%$ CI $50.47 \%$ to $51.64 \%$ ) of patients, the CCI was 0 . In $30.00 \%$ (95\% CI $29.45 \%$ to $30.52 \%$ ) the CCI was $1-2$. A CCI $3-4$ was found in $11.40 \%$ (95\% CI $11.03 \%$ to $11.78 \%$ ) of patients, while $7.56 \%$ (95\% CI $7.26 \%$ to $7.88 \%$ ) had a CCI of five or more.

More than half of all patients were assigned a nonspecific diagnosis relating to symptoms or incidents (ICD-10 classification chapters XVIII (symptoms, signs and abnormal clinical and laboratory findings, not elsewhere classified), XIX (injury, poisoning and certain other consequences of external causes) and XXI (factors influencing health status and contact with health services), $19 \%$ were registered with diseases within the circulatory system and $8.9 \%$ with diseases within the respiratory system (table 1 ).

\section{Mortality and factors associated with death following first MECU contact}

The cumulated 30-day mortality rate following first MECU contact was $16.2 \%$ (95\% CI $15.8 \%$ to $16.6 \%$ ). This includes 3211 patients declared dead at the scene $(9.8 \%)$. For patients admitted to hospital alive, the 30-day mortality rate was $5.7 \%$ (95\% CI $5.4 \%$ to $6.0 \%$ ). For patients admitted to hospital alive, the cumulated 90-day mortality was $8.1 \%$ (95\% CI $7.8 \%$ to $8.5 \%$ ), while the cumulated 2-year mortality was $16.4 \%$ (95\% CI $16.0 \%$ to $16.8 \%$ ). In patients treated by the MECU, mortality rates were extremely high compared with mortality rates of the background population. The OR for death compared with the background population ranged from over 8900 observed in men aged $10-19$ years at $0-7$ days following the first contact with the MECU, gradually decreasing to 1.25 for men above 90 years at 91 days, 2 years following the first MECU contact.

The survival estimates for the total population and for different diagnostic subpopulations are presented in online supplementary figures S2 and S3. The median follow-up time was 962 days, IQR 178 days-1931 days. For all categories of patients, the cumulated short-term mortality rate was very high followed by a more moderate long-term mortality rate (figure 3 ).

Increasing age, increasing CCI and hospitalisation within the last 180 days but not response time were all associated with short and long-term mortality rates (table 2).

\section{DISCUSSION}

\section{Principal findings}

From its inauguration in 1 May 2006 until 31 December 2014, the MECU in Odense, Denmark, servicing 250000 people, performed 13.1 missions per day. Of these missions, $79.2 \%$ resulted in patient contact. One mission in six was cancelled by the ambulance before the MECU obtained contact with the patient. One in 10 of the patients treated by the MECU was released at the scene after treatment thus obviating hospital admission. Nearly one patient out of 10 was declared dead at the scene. One in six MECU patients was dead at the scene or died within 30 days of the first contact. As the MECU is dispatched to all lifeless patients unless it is obvious from information given by the caller that there are reliable and unambiguous signs of death, some of the patients encountered by the MECU were dead and beyond resuscitation at the time of initial contact or even at the time of the caller's contact with the dispatch centre. When corrected for patients that were already dead at the arrival of the MECU, the mortality rate was up to three times as high as the mortality rate in the general patient population in the emergency department or in patients 
Figure 1 Flow chart depicting mobile emergency care unit missions in the observation period. ICD-10 diagnosis groups not represented in the material not shown.

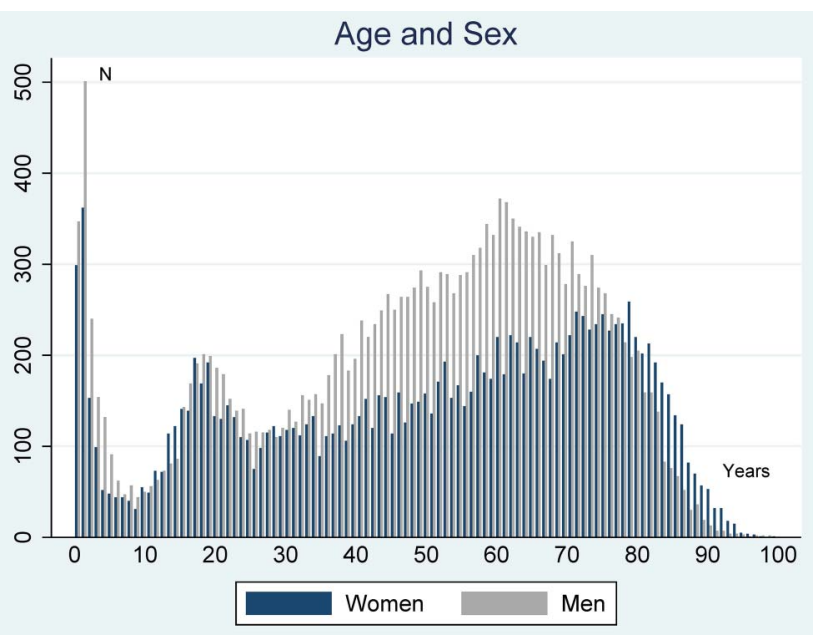

Figure 2 Distribution of patients' age and sex. Median age for women 58 years (31-77) Median age for men 56 years (34-71) $(p<0.001)$.

brought to the hospital in ambulances without the need for MECU intervention. ${ }^{33}$

The OR for death in the days immediately following a first MECU contact was very high. Although gradually decreasing from 3 months after first MECU contact, the

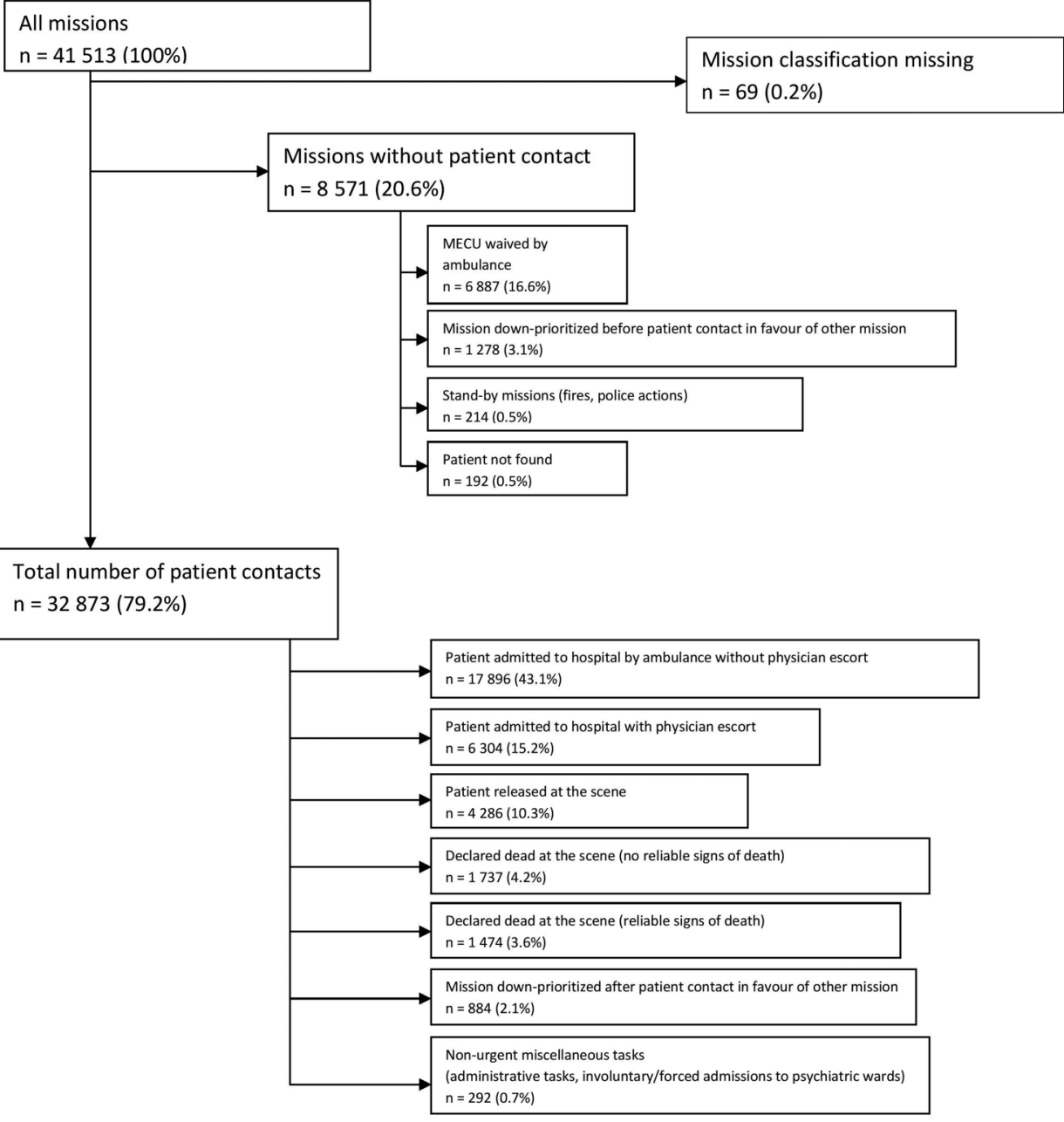

mortality rate following a first episode requiring treatment by a MECU did not fall to the level of the background population even at 2 years after the encounter. To the best of our knowledge, this is the first report of OR for death following a first episode requiring MECU assistance.

We have found that factors associated with death in the aftermath of a prehospital incident requiring the assistance from the MECU include advancing age and the male sex, and an increasing burden of chronic illness (as defined by increasing CCI) and an increasing number of weeks admitted to hospital in 180 days leading up to this event.

In the general population serviced by the MECU, we were unable to establish any association between hazard rate and MECU response time. When performing subanalysis of patients treated for cardiac arrest, there was still no association between MECU response time and outcome from 0 to 7 days when adjusted for sex, age, comorbidity or admission to hospital in 180 days preceding the incidence (see online supplementary table S1).

\section{Strengths and limitations}

The strength of the present study is the low number of patients lost to follow-up. This is in particular due to the Danish Civil Registration System in which each resident 
Table 1 Distribution of diagnoses according to WHO ICD-10 classification system

\begin{tabular}{|c|c|c|c|c|}
\hline $\begin{array}{l}\text { ICD-10 } \\
\text { chapter }\end{array}$ & Diagnosis group & & $\mathbf{n}$ & $\begin{array}{l}\text { Per cent } \\
(95 \% \mathrm{Cl})\end{array}$ \\
\hline Chapter I & Certain infectious and parasitic diseases & (A00-B99) & 180 & $0.56(0.48$ to 0.64$)$ \\
\hline Chapter IV & Endocrine, nutritional and metabolic diseases & (E00-E90) & 869 & 2.70 (2.52 to 2.88$)$ \\
\hline Chapter V & Mental and behavioural disorders & (F00-F99) & 793 & 2.46 (2.30 to 2.64$)$ \\
\hline Chapter VI & Diseases of the nervous system & (G00-G99) & 830 & 2.58 (2.41 to 2.76$)$ \\
\hline Chapter IX & Diseases of the circulatory system & $(100-199)$ & 6234 & $19.36(18.93$ to 19.79$)$ \\
\hline Chapter X & Diseases of the respiratory system & (J00-J99) & 2867 & $8.90(8.59$ to 9.22$)$ \\
\hline Chapter XI & Diseases of the digestive system & (K00-K93) & 390 & 1.21 (1.09 to 1.34$)$ \\
\hline Chapter XIII & $\begin{array}{l}\text { Diseases of the musculoskeletal system and connective } \\
\text { tissue }\end{array}$ & (M00-M99) & 262 & 0.81 (0.72 to 0.97$)$ \\
\hline Chapter XIV & Diseases of the genitourinary system & (N00-N99) & 60 & $0.19(0.14$ to 0.24$)$ \\
\hline Chapter XV & Pregnancy, childbirth and the puerperium & (000-099) & 97 & 0.30 (0.24 to 0.37$)$ \\
\hline Chapter XVI & Certain conditions originating in the perinatal period & (P00-P96) & 13 & $0.04(0.02$ to 0.07$)$ \\
\hline $\begin{array}{l}\text { Chapter } \\
\text { XVIII }\end{array}$ & $\begin{array}{l}\text { Symptoms, signs and abnormal clinical and laboratory } \\
\text { findings, not elsewhere classified }\end{array}$ & (R00-R99) & 7677 & $23.84(23.38$ to 24.31$)$ \\
\hline Chapter XIX & $\begin{array}{l}\text { Injury, poisoning and certain other consequences of external } \\
\text { causes }\end{array}$ & (S00-T98) & 4790 & $14.87(14.49$ to 15.27$)$ \\
\hline \multirow[t]{2}{*}{ Chapter XXI } & $\begin{array}{l}\text { Factors influencing health } \\
\text { status and contact with health services }\end{array}$ & (Z00-Z99) & 7140 & 22.17 (21.72 to 22.63$)$ \\
\hline & & & 32202 & 100.00 \\
\hline
\end{tabular}

is assigned a unique personal identifier and the fact that according to executive orders issued by the Danish Ministry of Health, a physician is obligated to register any treatment administered to patients. ${ }^{25} 34$ The low number of patients lost to follow-up also reflects that almost all patients were referred to one hospital aiding the subsequent identification of initially unidentified patients performed by a medical secretary at the MECU.

The basic patient characteristics in this study are very similar to those reported in a Norwegian paper. ${ }^{24}$ With the Scandinavian systems being almost identical, ${ }^{6}$ it is possible that the results of this study may prove to be generalisable for Scandinavia.

A considerable limitation of our study is that the use of only a single ICD-10 code to classify these patients may reduce the validity of our results. Comparisons with other systems would have been easier if our classification system had been based on the International Classification of Primary Care system (ICPC-2) describing mostly symptoms, thus probably fitting the prehospital population better. ${ }^{35}$

Another limitation of the study is that the study addresses patients cared for by one organisation only.

However, the basic characteristics of the patients are almost identical to a recent Danish study from another part of the country, the region of northern Jutland. ${ }^{23}$

The diagnoses comprising the calculation of the CCI are all extracted from admission at hospitals or outpatient treatments at hospitals. Thus, treatments administered at the general practitioners are not routinely collected at the National Patient register. This is a significant limitation of our study, potentially giving rise to residual confounding as the illnesses of some patients treated at the general practitioner thus may not be registered.
A further significant limitation of our study is that an exact measure of response time is difficult to obtain. The response time as perceived by the patient is the time that elapses from the patient obtains first contact with the dispatch centre and until the ambulance, or MECU, reaches the patient. However, in Denmark, traditionally, response times have been reported as time elapsed from the ambulance entrepreneur is handed the task and until the ambulance is brought to a standstill at the address (see online supplementary figure S4). This discrepancy between reported response time and patient's perceived response time has received little attention. In most studies, the response times reported did not necessarily reflect the time elapsed from contact with the dispatch centres to the emergency medical system had patient contact, but rather the time elapsed until the ambulance was at a standstill at the scene. ${ }^{36-38}$ Other definitions have been applied, defining response time as the time elapsed from determination of the patient's chief symptom and until ambulance arrival at the scene. ${ }^{39}$ Arrival at the scene is not necessarily coincident with patient contact. In high-rise buildings, a delay of 3-4.9 min was reported from the arrival of the ambulance at the scene to patient contact was achieved. ${ }^{40}$ The term 'response time' is thus in itself not accurate, rather it needs addition of 1-2 min to reflect the response time as perceived by the patient. As this additional time is identical for all emergency runs, this probably does not make comparisons within emergency medical systems impossible.

\section{Other studies}

Comparing this study with other studies describing the prehospital population serviced by anaesthesiologist-manned 
Figure 3 Graphical presentation of OR of death following the first contact with mobile emergency care unit (MECU). Note that the scaling of the $y$-axis differs on the two graphs.
Mortality following first MECU contact
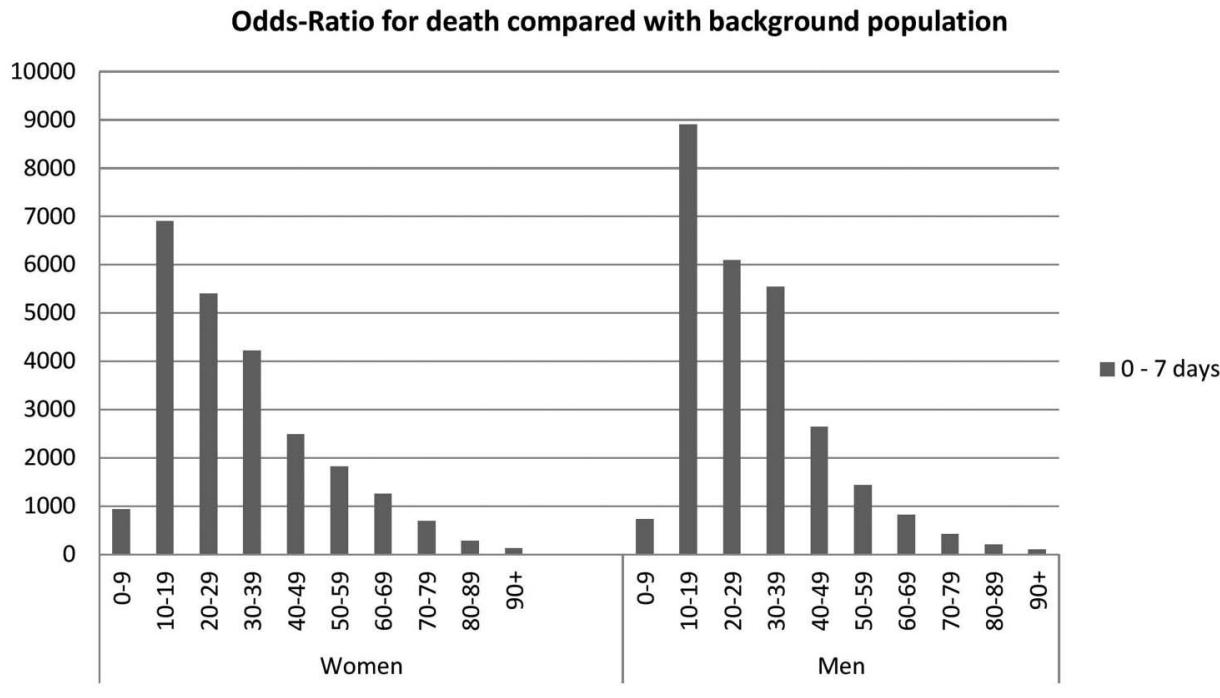

Mortality following first MECU contact

Odds-Ratio for death compared with background population

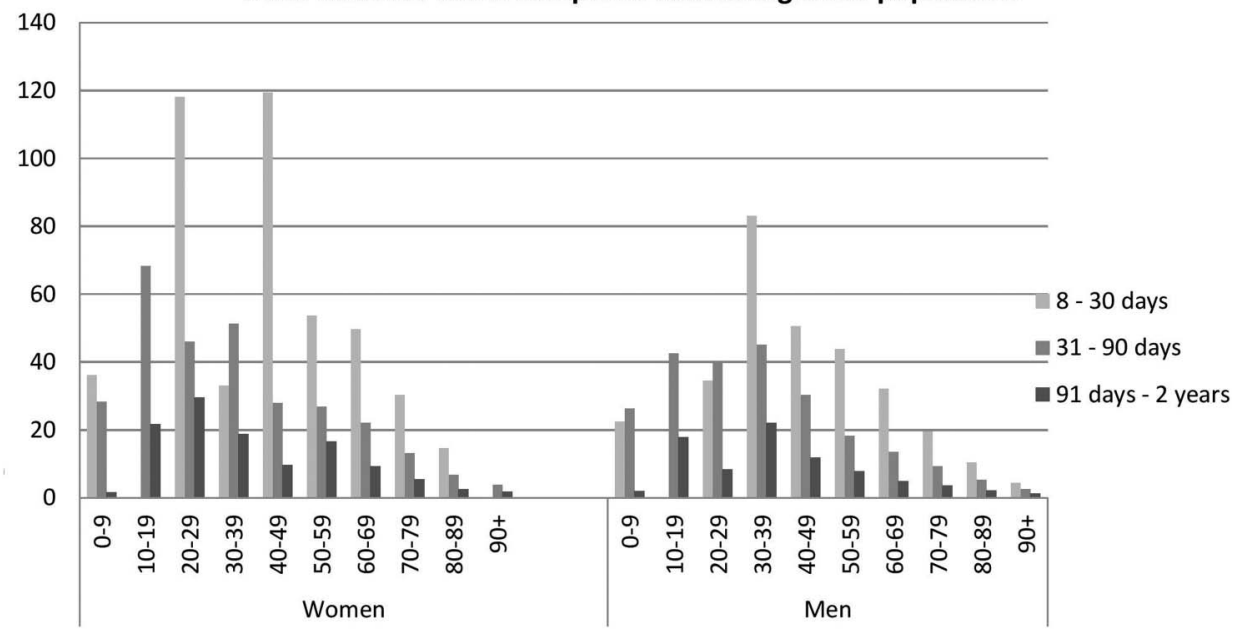

units, the number of ambulance runs and the demographic distribution of patients corresponds well to a similar study in a Norwegian prehospital emergency population serviced by a MECU. ${ }^{24}$ Although not identical, our distribution of missions is also in line with a study by Krüger et $a l,{ }^{6}$ who, in a study including several Scandinavian anaesthesiologist-manned prehospital services, reported that $13 \%$ of patients were released at the scene following treatment. The same study reported that in $19 \%$ of the missions, the anaesthesiologist-manned unit was cancelled before patient contact by the first responding unit, usually an ambulance. ${ }^{6}$

In a study of the total population of prehospital emergency patients transported to hospital, Christensen et $a l^{23}$ reported that in $61.6 \%$ of cases, the first inhospital diagnoses assigned to a general prehospital population were primarily within the ICD-10 chapters XVIII (symptoms, signs and abnormal clinical and laboratory findings, not elsewhere classified), XIX (injury, poisoning and certain other consequences of external causes) and XXI (factors influencing health status and contact with health services). This corresponds well with our study.

A study by Zakariassen et al, based on the ICPC, ${ }^{35}$ reports that the medical problems encountered were primarily cardiovascular, loss of consciousness, respiratory or neurological. ${ }^{24}$ This is in concordance with our findings. Our findings that the diagnoses assigned to the patients following treatment are primarily observational diagnoses or diagnoses describing a specific event are also in line with previous studies of patients encountered within an emergency department. ${ }^{41}$ To the extent that a definitive diagnosis has been assigned to the patient, the distribution of patients with circulatory or respiratory diagnoses coincides with a study on the epidemiology of older adults using the emergency medical services. ${ }^{20}$

Regarding the influence of response time on the outcome, conflicting results have been reported. Although there are papers supporting the notion that 
Table 2 Prognostic factors of death after first MECU contact, 0-7 days; 8-30 days; $31-90$ days; 91 days -2 years. Data presented as crude hazard rate and adjusted hazard rate

\begin{tabular}{|c|c|c|c|c|c|}
\hline Time span & Parameter & $\begin{array}{l}\text { Crude hazard rate } \\
(95 \% \mathrm{Cl})\end{array}$ & p Value & $\begin{array}{l}\text { Adjusted hazard } \\
\text { rate }(95 \% \mathrm{Cl})\end{array}$ & p Value \\
\hline \multirow[t]{10}{*}{$0-7$ days } & Sex & & & & \\
\hline & Female (reference) & 1 & & 1 & \\
\hline & Male & $0.85(0.74$ to 0.98$)$ & 0.029 & $1.08(0.93$ to 1.25$)$ & 0.302 \\
\hline & Age (continuous) & 1.05 (1.04 to 1.05$)$ & $<0.001$ & 1.04 (1.04 to 1.05$)$ & $<0.001$ \\
\hline & Charlson Comorbidity Index & & & & \\
\hline & 0 (reference) & 1 & & 1 & \\
\hline & $1-2$ & 3.22 (2.68 to 3.86$)$ & $<0.001$ & $1.42(1.17$ to 1.72$)$ & $<0.001$ \\
\hline & $>2$ & 4.75 (3.95 to 5.72$)$ & $<0.001$ & 1.55 (1.26 to 1.90$)$ & $<0.001$ \\
\hline & $\begin{array}{l}\text { Weeks admitted to hospital } 180 \text { days prior } \\
\text { to first contact }\end{array}$ & 1.15 (1.12 to 1.18$)$ & $<0.001$ & 1.08 (1.04 to 1.12$)$ & $<0.001$ \\
\hline & Response time (continuous) & $0.97(0.96$ to 0.99$)$ & $<0.001$ & 1.00 (0.99 to 1.02$)$ & 0.539 \\
\hline \multirow[t]{10}{*}{$8-30$ days } & Sex & & & & \\
\hline & Female (reference) & 1 & & 1 & \\
\hline & Male & $0.93(0.78$ to 1.11$)$ & 0.442 & $1.14(0.96$ to 1.37$)$ & 0.136 \\
\hline & Age (continuous) & 1.05 (1.05 to 1.06$)$ & $<0.001$ & 1.04 (1.04 to 1.05$)$ & $<0.001$ \\
\hline & Charlson Comorbidity Index & & & & \\
\hline & 0 (reference) & 1 & & 1 & \\
\hline & $1-2$ & 5.10 (3.90 to 6.68$)$ & $<0.001$ & 2.22 (1.67 to 2.94$)$ & $<0.001$ \\
\hline & $>2$ & 11.65 (9.00 to 15.08$)$ & $<0.001$ & 3.59 (2.71 to 4.77$)$ & $<0.001$ \\
\hline & $\begin{array}{l}\text { Weeks admitted to hospital } \\
180 \text { days prior to first contact }\end{array}$ & $1.21(1.18$ to 1.24$)$ & $<0.001$ & $1.13(1.10$ to 1.17$)$ & $<0.001$ \\
\hline & Response time (continuous) & $0.98(0.96$ to 0.99$)$ & 0.006 & 1.01 (0.99 to 1.03$)$ & 0.266 \\
\hline \multirow[t]{10}{*}{$31-90$ days } & Sex & & & & \\
\hline & Female (reference) & 1 & & 1 & \\
\hline & Male & $0.98(0.83$ to 1.15$)$ & 0.813 & $1.22(1.03$ to 1.44$)$ & 0.019 \\
\hline & Age (continuous) & 1.05 (1.05 to 1.06$)$ & $<0.001$ & 1.04 (1.04 to 1.05$)$ & $<0.001$ \\
\hline & Charlson Comorbidity Index & & & & \\
\hline & 0 (reference) & 1 & & 1 & \\
\hline & $1-2$ & 5.88 (4.57 to 7.57$)$ & $<0.001$ & 2.51 (1.92 to 3.26$)$ & $<0.001$ \\
\hline & $>2$ & $13.19(10.33$ to 16.84$)$ & $<0.001$ & 3.93 (3.01 to 5.14$)$ & $<0.001$ \\
\hline & $\begin{array}{l}\text { Weeks admitted to hospital } \\
180 \text { days prior to first contact }\end{array}$ & $1.23(1.21$ to 1.25$)$ & $<0.001$ & $1.17(1.14$ to 1.20$)$ & $<0.001$ \\
\hline & Response time (continuous) & 0.96 (0.94 to 0.97$)$ & $<0.001$ & 0.99 (0.97 to 1.01$)$ & 0.178 \\
\hline 91 days- & Sex & & & & \\
\hline \multirow[t]{9}{*}{2 years } & Female (reference) & 1 & & 1 & \\
\hline & Male & $0.97(0.88$ to 1.05$)$ & 0.429 & 1.22 (1.11 to 1.33$)$ & $<0.001$ \\
\hline & Age (continuous) & 1.05 (1.05 to 1.06$)$ & $<0.001$ & 1.04 (1.04 to 1.05$)$ & $<0.001$ \\
\hline & Charlson Comorbidity Index & & & & \\
\hline & 0 (reference) & 1 & & 1 & \\
\hline & $1-2$ & 5.64 (4.96 to 6.43$)$ & $<0.001$ & 2.54 (2.22 to 2.91$)$ & $<0.001$ \\
\hline & $>2$ & $14.19(12.50$ to 16.11$)$ & $<0.001$ & 4.44 (3.86 to 5.10$)$ & $<0.001$ \\
\hline & $\begin{array}{l}\text { Weeks admitted to hospital } \\
180 \text { days prior to first contact }\end{array}$ & $1.21(1.20$ to 1.23$)$ & $<0.001$ & $1.13(1.12$ to 1.15$)$ & $<0.001$ \\
\hline & Response time (continuous) & 0.96 (0.96 to 0.97$)$ & $<0.001$ & $1.00(0.99$ to 1.00$)$ & 0.292 \\
\hline
\end{tabular}

reduced response times are associated with improved outcome, ${ }^{36}{ }^{39}$ our findings are in line with findings made by several other researchers, who have been unable to demonstrate any correlation between ambulance response time and hospital days, admissions, intensive care unit admissions or deaths in trauma victims. ${ }^{37} 3842$ When interpreting our findings, however, it is essential to consider that the response times reported here are those of the MECU. As the dispatch centre always dispatches the nearest available ambulance to an incident, only rarely does the MECU arrive first on the scene. Most of the MECU patients have thus been subjected to initial treatment by the ambulances. The interpretation that MECU response time is not associated with outcome should thus be made with caution.

\section{Interpretation}

We found that being exposed to an incident resulting in the need for treatment by the MECU was associated with a very high mortality rate. This association can be 
coupled with our findings that the burden of chronic disease in the population serviced by the MECU is low (more than half of the patients having a CCI of 0 ). Therefore, it can be interpreted that the first episode requiring treatment by the MECU is elicited by an acute life-threatening disease or by an accident. Another angle on our results may be that our finding that $50 \%$ of the patients are not diagnosed with chronic illness before the first encounter with the MECU may suggest that these patients are not regular users of the healthcare system. The possible explanation for an apparently healthy population suddenly requiring treatment by the MECU with an ensuing high mortality rate may be that the event leading up to the first MECU encounter is an exacerbation of a severe disease that hitherto may have gone undetected. These patients may thus have evaded the targeted interventions primary care has to offer. Knowledge of the increased mortality has the potential to increase the awareness and perhaps even improve the treatment of this vulnerable population with a potential for reducing severity of illness.

Only in a minority of patients is a specific diagnosis assigned prehospitally. One possible explanation for this apparent inability to establish an exact diagnosis prehospitally may be that the prehospital physician does not possess the same amount of diagnostic tools as the inhospital physician. There may also be a perception that the prehospital anaesthesiologist-manned unit is a limited or depletable resource, and that the unit is supposed to restrict the time spent with the patient and prepare for the next mission. A certain amount of time constraint may thus influence the diagnosing of the patient.

In line with suggestions by Christensen $e t a l{ }^{23}$ the large number of missions cancelled before patient contact is obtained and the large number of patients in whom treatment can be finalised at the scene may hint towards overtriage by the dispatch centre.

\section{Future research}

Previous studies on the association between socioeconomic factors and frequent hospital admissions and health outcomes suggests that studies on socioeconomic factors associated with increased use of the MECU are needed. ${ }^{43-45}$ We hypothesise that some users of the MECU are not regular users of the healthcare system and as such have evaded the targeted interventions primary care has to offer. This interpretation of our data suggests that further knowledge of the prehospital population may facilitate interventions aimed at preventing these events.

The accuracy of dispatch is another subject that needs investigation. As alluded to by other researchers, ${ }^{23}{ }^{46}$ the large number of cancelled MECU runs and the large number of patients that are released at the scene following treatment points towards overtriage. It is thus possible that the accuracy of the dispatchers is not sufficient. Knowledge of accuracy of the dispatch element of prehospital treatment may lead to better usage of resources.

\section{CONCLUSION}

Although less than half of the patients were diagnosed with specific chronic diseases before the first contact with a MECU, mortality following an incident requiring the assistance of an anaesthesiologist manned prehospital MECU was very high in the first 2 years following the incident. Mortality was associated with age, sex, comorbidity and weeks spent at hospital 180 days preceding the event. The intuitive notion that shorter response times should lead to improved patient outcome could not be supported in our study.

\section{Author affiliations}

${ }^{1}$ Mobile Emergency Care Unit, Department of Anaesthesiology and Intensive Care Medicine V, Odense University Hospital, Odense, Denmark

${ }^{2}$ Department of Clinical Research, University of Southern Denmark, Odense, Denmark

${ }^{3}$ Field of Prehospital Critical Care, Network for Medical Sciences, University of Stavanger, Stavanger, Norway

${ }^{4}$ Norwegian Air Ambulance Foundation, Drøbak, Norway

${ }^{5}$ Department of Anaesthesiology and Intensive Care Medicine V, Odense University Hospital, Odense, Denmark

${ }^{6}$ Department of Emergency Medicine, Odense University Hospital, Odense, Denmark

Contributors SM and ATL contributed to this manuscript with idea and design as well as acquisition of data, analysis of data and drafting and revising of the manuscript. HML and PT contributed to this manuscript with idea, design, drafting and revision of the manuscript. All authors read and approved the final manuscript.

Funding This research received no specific grant from any funding agency in the public, commercial or not-for-profit sectors.

\section{Competing interests None.}

Ethics approval The study was approved by the Danish Data Protection Agency (J.no. 2014-41-3305) and the Danish Health and Medicines Agency (J.no. 3-3013-682/1/).

Provenance and peer review Not commissioned; externally peer reviewed.

Data sharing statement No additional data are available.

Open Access This is an Open Access article distributed in accordance with the Creative Commons Attribution Non Commercial (CC BY-NC 4.0) license, which permits others to distribute, remix, adapt, build upon this work noncommercially, and license their derivative works on different terms, provided the original work is properly cited and the use is non-commercial. See: http:// creativecommons.org/licenses/by-nc/4.0/

\section{REFERENCES}

1. Terkelsen CJ, Sørensen JT, Maeng M, et al. System delay and mortality among patients with STEMI treated with primary percutaneous coronary intervention. JAMA 2010;18:763-71.

2. Angus DC, van der Poll T. Severe sepsis and septic shock. N Engl J Med 2013;369:840-51.

3. Vincent JL, De.Backer D. Circulatory shock. $N$ Engl J Med 2013;369:1726-34.

4. Lees KR, Bluhmki E, von Kummer R, et al. Time to treatment with intravenous alteplase and outcome in stroke: an updated pooled analysis of ECASS, ATLANTIS, NINDS, and EPITHET trials. Lancet 2010;375:1695-703.

5. Lossius HM, Søreide E, Hotvedt R, et al. Prehospital advanced life support provided by specially trained physicians: is there a benefit in terms of life years gained? Acta Anaesthesiol Scand 2002;46:771-8. 
6. Krüger AJ, Lossius HM, Mikkelsen S, et al. Pre-hospital critical care provided by physician-staffed pre-hospital services in Scandinavia: a prospective population based study. Acta Anaesthesiol Scand 2013;57:1175-85

7. The Danish Ministry of Health. Executive order on prehospital services. https://www.retsinformation.dk/Forms/R0710.aspx? id $=181681$ (accessed 14 Nov 2016)

8. Andersen MS, Johnsen SP, Sorensen JN, et al. Implementing a nationwide criteria-based emergency medical dispatch system: a register-based follow-up study. Scand J Trauma Resusc Emerg Med 2013;21:53.

9. Stiell IG, Nesbitt LP, Pickett W, et al. The OPALS Major Trauma Study: impact of advanced life-support on survival and morbidity. CMAJ 2008;178:1141-52.

10. Bøtker MT, Bakke SA, Christensen EF. A systematic review of controlled studies: do physicians increase survival with prehospital treatment? Scand J Trauma Resusc Emerg Med 2009;17:12

11. Wilson $\mathrm{MH}$, Habig K, Wright $\mathrm{C}$, et al. Pre-hospital emergency medicine. Lancet 2015;386:2526-34.

12. Hagihara A, Hasegawa M, Abe T, et al. Physician presence in an ambulance car is associated with increased survival in out-of-hospital cardiac arrest: a prospective cohort analysis. PLOS ONE 2014;9:e84424.

13. Mikkelsen S, Krüger AJ, Zwisler ST, et al. Outcome following physician supervised pre-hospital resuscitation: a retrospective study. BMJ Open 2015;5:e006167.

14. Böttiger BW, Bernhard M, Knapp J, et al. Influence of EMS-physician presence on survival after out-of-hospital cardiopulmonary resuscitation: systematic review and meta-analysis. Crit Care 2016;20:4

15. Fevang E, Lockey D, Thompson J, et al. The top five research priorities in physician-provided pre-hospital critical care: a consensus report from a European research collaboration. Scand J Trauma Resusc Emerg Med 2011;19:57.

16. Shah MN, Cushman JT, Davis CO, et al. The epidemiology of emergency medical services use by children: an analysis of the National Hospital Ambulatory Medical Care Survey. Prehosp Emerg Care 2008;12:269-76.

17. Miller MK, Dowd M, Gratton MC, et al. Pediatric out-of-hospital emergency medical services utilization in Kansas City, Missouri. Acad Emerg Med 2009;16:526-31.

18. Wofford JL, Moran WP, Heuser MD, et al. Emergency medical transport of the elderly: a population based study. Am J Emerg Med 1995; 13:297-300.

19. Gerson LW, Skvarch L. Emergency medical service utilization by the elderly. Ann Emerg Med 1982;11:610-2.

20. Shah MN, Bazarian JJ, Lerner EB, et al. The epidemiology of emergency medical services use by older adults: an analysis of the National Hospital Ambulatory Medical Care Survey. Acad Emerg Med 2007;14:441-7.

21. Keskinoglu P, Sofuoglu T, Ozmen O, et al. Older people's use of pre-hospital emergency medical services in Izmir, Turkey. Arch Gerontol Geriatr 2010;50:356-60.

22. Lerner EB, Shah MN, Swor RA, Comparison of the 1999 and 2006 trauma triage guidelines: where do patients go? Prehosp Emerg Care 2011;15:12-7.

23. Christensen EF, Larsen TM, Jensen FB, et al. Diagnosis and mortality in prehospital emergency patients transported to hospital: a population-based and registry-based cohort study. BMJ Open 2016;6:e011558.

24. Zakariassen E, Burman RA, Hunskaar S. The epidemiology of medical emergency contacts outside hospitals in Norway-a prospective population based study. Scand J Trauma Resusc Emerg Med 2010;18:9.

25. Schmidt M, Pedersen L, Sørensen HT. The Danish Civil Registration System as a tool in epidemiology. Eur J Epidemiol 2014; 29:541-9.

26. Lynge E, Sandegaard JL, Rebolj M. The Danish National Patient Register. Scand J Public Health 2011;39:30-3.
27. StatBank Denmark. http://www.statistikbanken.dk/statbank5a/default. asp?w=1536 (accessed 14 Nov 2016)

28. World Health Organisation. International statistical classification of diseases and related health problems 10th revision. http://apps.who. int/classifications/icd10/browse/2016/en (accessed 14 Nov 2016)

29. Charlson ME, Pompei P, Ales KL, et al. A new method of classifying prognostic comorbidity in longitudinal studies: development and validation. J Chronic Dis 1987;40:373-83.

30. Grambsch PM, Therneau TM, Fleming TR. Diagnostic plots to reveal functional form for covariates in multiplicative intensity models. Biometrics 1995;51:1469-82.

31. Krüger AJ, Lockey D, Kurola J, et al. A consensus-based template for documenting and reporting in physician-staffed pre-hospital services. Scand J Trauma Resusc Emerg Med 2011;19:71.

32. von Elm E, Altman DG, Egger M, et al. The strengthening the reporting of observational studies in epidemiology (STROBE) statement: guidelines for reporting observational studies. Int J Surg 2014;12:1495-9.

33. Kristensen AKB, Holler JG, Mikkelsen S, et al. Systolic blood pressure and short-term mortality in the emergency department and prehospital setting: a hospital-based cohort study. Crit Care 2015;19:158.

34. The Danish Ministry of Health. Executive order on medical records. $\mathrm{http}: / / \mathrm{stps} . \mathrm{dk} / \mathrm{da} /$ sundhedsprofessionelle-og-myndigheder/ autorisation,-anerkendelser-og-selvstaendigt-virke/autorisation-ogpligter/journalfoering (accessed 14 Nov 2016)

35. World Health Organization: international classification of primary care, (ICPC-2). http://www.kith.no/templates/kith_WebPage 1062.aspx (accessed 14 Nov 2016).

36. Pons PT, Haukoos JS, Bludworth W, et al. Paramedic response time: does it affect patient survival? Acad Emerg Med 2005;12:594-600

37. Blanchard IE, Doig CJ, Hagel BE, et al. Emergency medical services response time and mortality in an urban setting. Prehosp Emerg Care 2012;16:142-51.

38. Weiss S, Fullerton L, Oglesbee S, et al. Does ambulance response time influence patient condition among patients with specific medical and trauma emergencies? South Med $J$ 2013:106:230-5.

39. Blackwell TH, Kaufman JS. Response time effectiveness: comparison of response time and survival in an urban emergency medical services system. Acad Emerg Med 2002;9:288-95.

40. Drennan IR, Strum RP, Byers A, et al. Out-of-hospital cardiac arrest in high-rise buildings: delays to patient care and effect on survival. CMAJ 2016;188:413-19.

41. Langlo NM, Orvik AB, Dale J, et al. The acute sick and injured patients: an overview of the emergency department patient population at a Norwegian University Hospital Emergency Department. Eur J Emerg Med 2014;21:175-80.

42. Blackwell TH, Kline JA, Willis JJ, et al. Lack of association between prehospital response times and patient outcomes. Prehosp Emerg Care 2009:13:444-50.

43. Low LL, Tay WY, Ng MJ, et al. Frequent hospital admissions in Singapore: clinical risk factors and impact of socioeconomic status. Singapore Med J. 2016. doi:10.11622/smedj.2016110 [Epub ahead of print 17 Jun 2016]

44. Pickett KE, Pearl M. Multilevel analyses of neighbourhood socioeconomic context and health outcomes: a critical review. $J$ Epidemiol Community Health 2001;55:111-22.

45. Coady SA, Johnson NJ, Hakes JK, et al. Individual education, area income, and mortality and recurrence of myocardial infarction in a Medicare cohort: the National Longitudinal Mortality Study. BMC Public Health 2014;14:705.

46. Møller TP, Ersbøll AK, Tolstrup JS, et al. Why and when citizens call for emergency help: an observational study of 211,193 medical emergency calls. Scand J Trauma Resusc Emerg Med 2015;23:88 